\title{
THE ANALYTIC. HIERARCHY PROCESS AND LINEAR PROGRAMMING IN HUMAN RESOURCE ALLOCATION
}

\author{
Thomas L. Saaty \\ SAATY@vms.cis.pitt.edu \\ University of Pittsburgh \\ Kirti Peniwati \\ Lembaga.PPM36@graha.sprint.com \\ Institute for Management Education and Development \\ J1. Menteng Raya 9, Jakarta, Indonesia
}

\begin{abstract}
The Analytic Hierarchy Process (AHP) provides a way to rank the alternatives of a problem by deriving ratio scales to represent these ranks. A question that occurs in practice is: what is the best combination of alternatives that has the largest sum of priorities-across different criteria and satisfies given constraints. This leads one to consider the interface between the AHP and the combinatorial approach inherent in Linear Programming (LP). The priorities of the alternatives often serve as coefficients of the objective function of an LP probiem. The constraints are determined from existing measurements such as the range of the number of employees needed and the salaries required for various jobs. It is shown how the absolute measurement mode of the AHP is used to prioritize organizational positions and applicants for these positions and determine the positions to be filled along with the applicants to fill them. A more general concern is how to obtain the coefficients of the constraints themselves as priorities and " how to establish numerical bounds on the constraints. This paper is concerned with examples of an objective function whose coefficients are derived through the AHP and whose constraints involve tangible coefficients. Brief discussion of optimization where the coefficients of an entire LP problem are determined by the AHP and whose variables are tangibles is also given with a simple example.
\end{abstract}

\section{INTRODUCTION}

This is an expository article about the use of the Analytic Hierarchy Process (AHP) as a multicriteria prioritization approach for resource allocation. In particular we apply absolute measurement of the AHP to the optimal assignment of human resources. Special emphasis is placed on the measurement of intangible criteria and on their incorporation into the allocation process. The AHP and Linear Programming (LP) are brought together to rate and derive the best combination of people assigned to jobs. Use of the AHP enables us to address the issue of synergy between people that affects their qualification and whether they are selected singly or as a group.

In a comprehensive review of Human Resource Planning, James A. Craft (1995) speaks of Human Resource Planning as a process of moving an organization to its desired position with the right kind of people in the right job at the right time to maximize value creating activity ... to help employers effectively meet human resource requirements.

An organization's goals, objectives, and resource constraints are needed in this process.

Much of the literature in Human Resource Planning deals with future thinking by placing emphasis on forecasting needs (Fisher, 1993; Mathis and Jackson, 1991; Milovich and Boudreau, 1991; Noe et.al; 1994; Shuler and Huber, 1993). The problem is how to implement the plan to satisfy the needs. A key implementation is that of staffing the organization through selection and allocation when forecast needs have been established. How can this be done in an optimal manner with consistency in achieving the 
organizational goais? The AHP offers new possibilities for tackling this problem because it is a multicriteria methodology that deals with both tangibles and intangibles in an integrated and comprehensive manner within a hierarchic structure that relates people to the criteria and to the goals of the organization. As a mathematical procedure, it uses both available quantitative data along with the judgments of decision makers and experts to arrive at an overall optimum answer. Through the prioritization process, one is able to determine the relative contribution of each alternative to the goal of the organization, whether that alternative is a job position or a particular individual with his or her qualifications. However, when a combination of positions or of individuals that best satisfies the goal subject to resource constraints is required, one needs to use LP.

Our purpose here is to illustrate the use of absolute measurement in the AHP along with LP to obtain optimum human resource allocation. LP is widely used in the literature and is more of a technicai subject. The problem is how to use the measurement derived from the AHP to formulate an LP model which is then solved using a standard software program like LINDO.

\section{Examples of Applications: Who to hire and how many?}

\section{Human Resource Requirements in Biological Detection Systems (Gabler and Prado, 1994)}

Biological Detection Systems (BDS), a small biotech start-up firm located just north of Pittsburgh, is attempting to position itself for future growth by expanding its employee base. It has identified areas in Marketing, Manufacturing, and Research and Development which need increased manpower. BDS has $\$ 520,000$ to invest in new employees. Therefore it wants to select those applicants which will provide the most benefit to the organization. For proprietary reason, we do not provide a detailed description of the company's operation. The company's customer base has expanded from 75 users in 1992 to over 500 through the third quarter of 1994, and BDS expects the increase to continue at this rapid pace through 1995 and 1996 . The positions to be filled are listed and briefly described below.

\section{Potential Positions for New Hires}

\begin{tabular}{||l|l|l||}
\hline Position. & Department & Description \\
\hline V.P. of Marketing & Marketing & $\begin{array}{l}\text { Take BDS products into use in the clinical or "real world" } \\
\text { applications }\end{array}$ \\
\hline $\begin{array}{l}\text { Customer Service } \\
\text { Representative }\end{array}$ & Marketing & Take orders, answer phones, first line of customer support. \\
\hline Marketing Assistant & Marketing & $\begin{array}{l}\text { Maintain customer database, organize mailing pieces and } \\
\text { advertisements. }\end{array}$ \\
\hline Shipping Clerk & Marketing & Package and ship products to customers. \\
\hline Lab Technician & R\&D & Carry out experiments as specified by the lab supervisor. \\
\hline Operations Supervisor & Manufacturing & $\begin{array}{l}\text { Schedule the production of reagents according to customer } \\
\text { needs. Oversee operations. }\end{array}$ \\
\hline Chemists & Manufacturing & Manufacture dyes. \\
\hline Biologists & Manufacturing & Puts dyes on the biologicals. \\
\hline Quality Specialists & Manufacturing & $\begin{array}{l}\text { Make sure products meet government regulations. } \\
\text { Calibrate equipment. }\end{array}$ \\
\hline
\end{tabular}

The object is to determine the optimum number of vacancies in each position and who best to hire to fill these positions, to satisfy the following organizational objectives: (1) to increase its marketing effort in the clinical market areas, (2) to satisfy future demand for its product, (3) to better insure product quality, (4) to develop new products, (5) to manage employees

When evaluating candidates, BDS is confronted with a large number of tradeoffs over a diverse set of criteria. All the applicants for a single position will be rated and evaluated based on the same set of criteria for that position and priorities derived for each individual. 


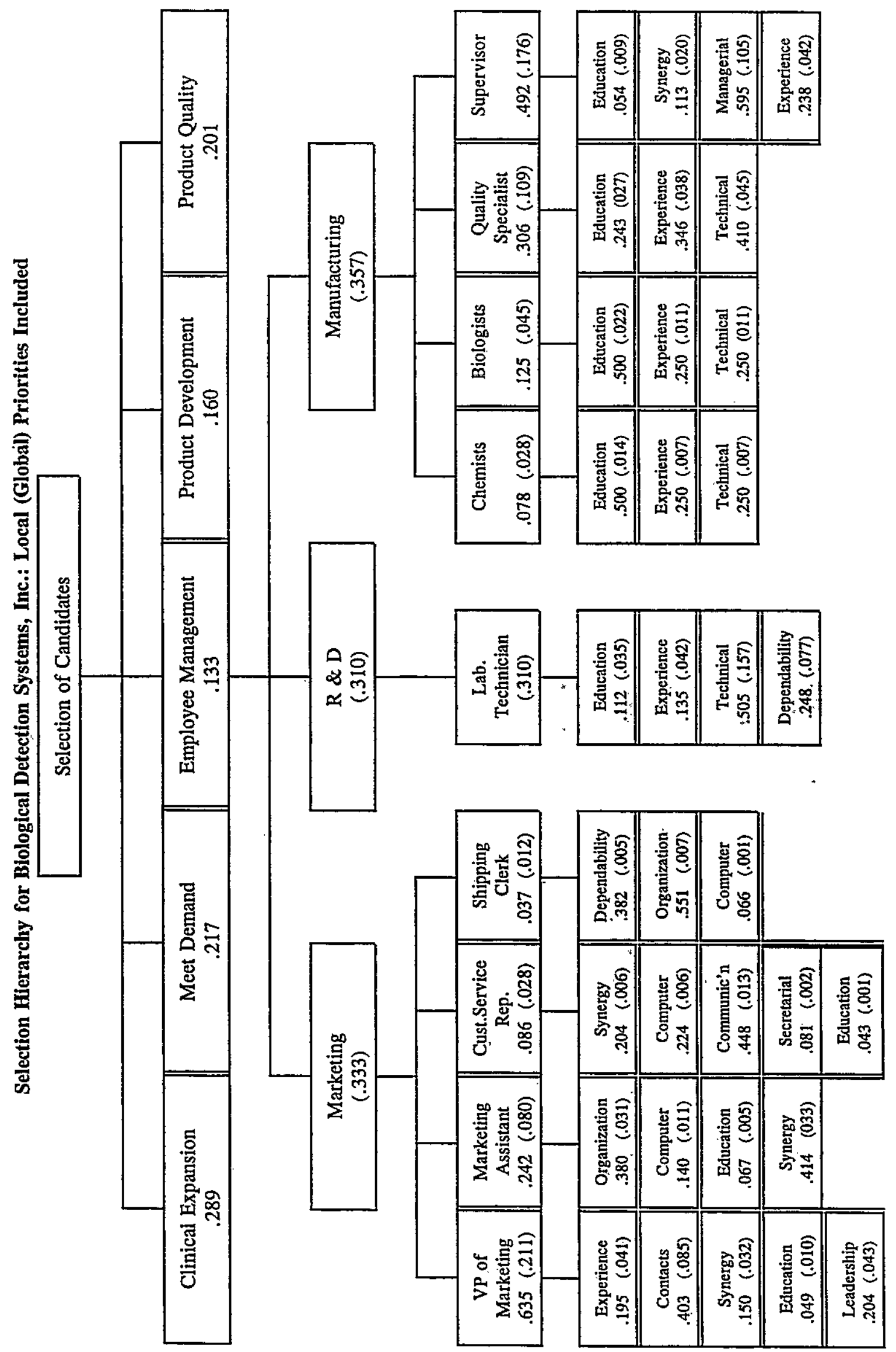


The goal of the hierarchy above is to allocate the most qualified candidates to the various departments. The second level represents the five objectives of the company, followed by the three departments for which applicants will be hired in the third level. Level four identifies the positions that need to be filled within each department. The criteria for evaluating the candidates for each position are located in the fifth level. For example, VP of Marketing will be evaluated based on experience, contacts, synergy, education, and leadership. Experience will be measured in the number of years of industry experience the person has, contacts is used to evaluate the number of contacts the candidate has in the clinical health care industry, synergy attempts to determine how well the individual will fit within the organization, education is used to evaluate the candidates' formal education, and leadership attempts to measure a candidate's general leadership skills.

To implement absolute measurement, each criterion is divided into several intensity ranges to differentiate the qualification of the candidates with respect to that criterion. These intensities are located in level six. For example, the evaluation criteria for VP Marketing has the following intensities: experience, which is divided into three intensities of high (corresponds to $15+$ years of experience), medium (6 to 15 years), and low (5 years or less). Contacts and leadership are also divided into high, medium, and low; synergy into extreme, high, medium, and low with extreme rating awarded to individuals who are judged to be a perfect fit with BDS. Education is divided into PhD, Masters, Bachelor, and Secondary. The selection criteria and their intensities for each job together with their relative importance are listed below:

\section{Selection Criteria}

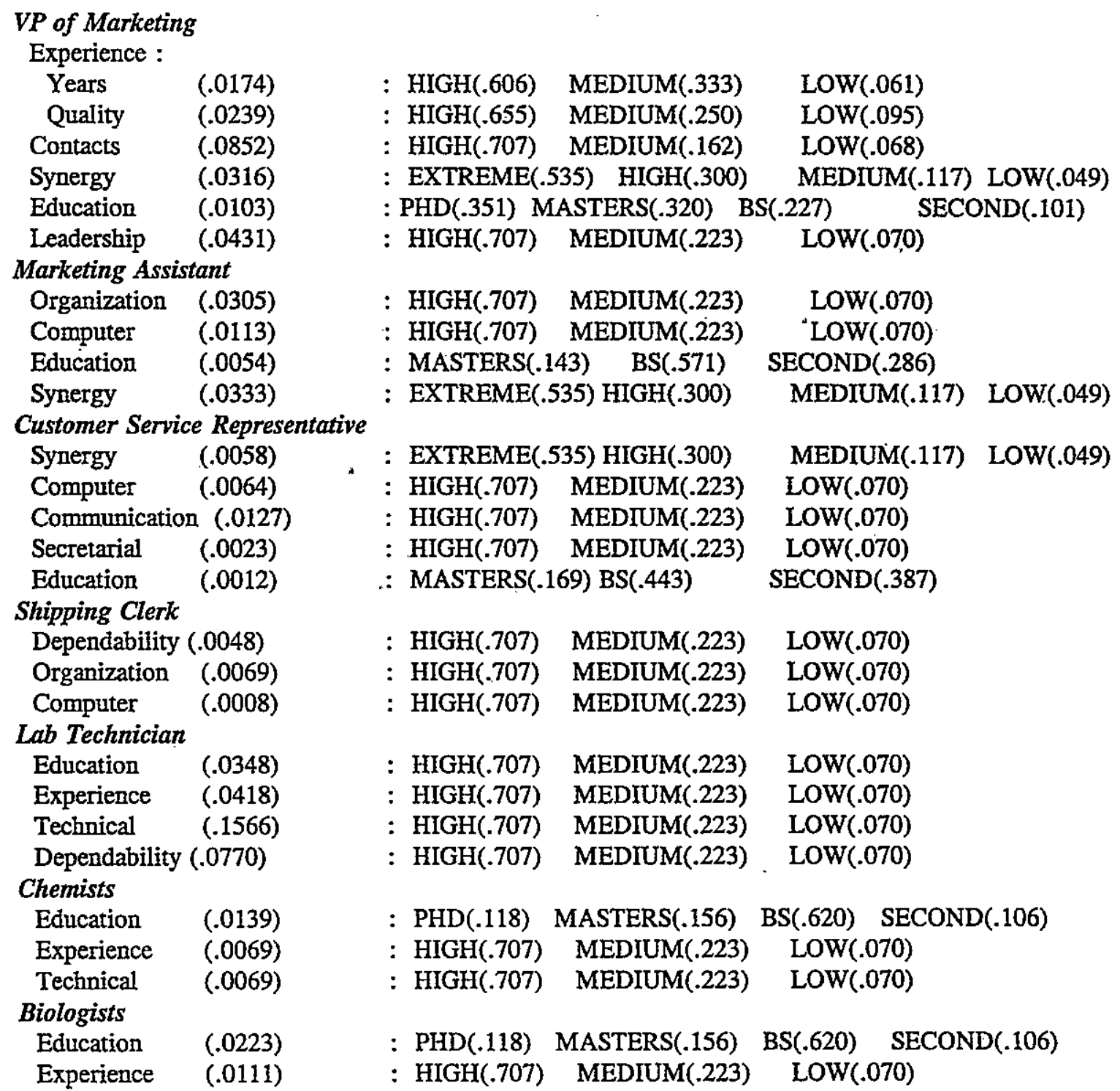




\begin{tabular}{|c|c|c|c|c|}
\hline Technical & $(.0111)$ & : HIGH(.707) & MEDIUM(.223) & LOW $(.070)$ \\
\hline \multicolumn{5}{|c|}{ Quality Specialists } \\
\hline Education & $(.0265)$ & : PHD(.122) & MASTERS(.487) & $\operatorname{SECOND}(.073)$ \\
\hline Experience & $(.0378)$ & : HIGH(.707) & MEDIUM(.223) & Low $(.070)$ \\
\hline Technical & $(.0448)$ & : HIGH(.707) & MEDIUM(.223) & LOW(.070) \\
\hline \multicolumn{5}{|l|}{ Supervisor } \\
\hline Education & $(.0094)$ & : $\operatorname{PHD}(.610)$ & MASTERS(.2367) & $\operatorname{SECOND}(.038)$ \\
\hline Synergy & (.0198) & : EXTREME( & .535) HIGH(.300) & MEDIUM(.117) LOW(.049) \\
\hline Managerial & $(.1046)$ & : HIGH(.707) & MEDIUM(.223) & $\operatorname{LOW}(.070)$ \\
\hline Experience & $(.0418)$ & : HIGH(.707) & MEDIUM(.223) & LOW $(.070)$ \\
\hline
\end{tabular}

\section{Human Resource Needs at BDS}

The salary and minimum and maximum number of personnel required in each position are given below:

Salary and Number of Personnel Required

\begin{tabular}{|l|r|c|c|}
\hline Position & $\begin{array}{l}\text { Salary \& } \\
\text { Benefits }\end{array}$ & Min & Max \\
\hline V.P. Marketing & $\$ 120,000$ & 1 & 1 \\
\hline Marketing Assistant & $\$ 50,000$ & 1 & 1 \\
\hline Customer Service Rep. & $\$ 40,000$ & 1 & 3 \\
\hline Shipping Clerk & $\$ 40,000$ & 0 & 1 \\
\hline Lab Technician & $\$ 40,000$ & 2 & 5 \\
\hline Chemists & $\$ 50,000$ & 0 & 1 \\
\hline Biologists & $\$ 45,000$ & 1 & 2 \\
\hline Quality. Specialists & $\$ 70,000$ & 0 & 1 \\
\hline Operations Supervisor & $\$ 90,000$ & 1 & 1 \\
\hline
\end{tabular}

The nine positions are prioritized in terms of their contribution to the organizational objectives; four under Marketing, four under Manufacturing and one under R\&D. The priorities of each are multiplied by the relative number of positions in its group to the total of 9 and the result is then normalized. The criteria for evaluation are' then prioritized with respect to each of the positions, and the criteria intensities (not shown in the hierarchy) are prioritized with respect to their corresponding criterion. The applicants are then evaluated by assigning each the appropriate intensity for each criterion according to their qualifications. Since each applicant will be evaluated for a single position only, each will be rated according to the criteria for that position. His or her rating for the criteria for the other positions will be zero. Here are examples:

Evaluation of Applicants: VP Marketing

\begin{tabular}{||c|c|c|c|c|c|c||}
\hline \multirow{2}{*}{} & \multicolumn{2}{|c|}{ Experience } & Contacts & Synergy & Educa-tion & Leadership \\
\cline { 2 - 3 } & Years & Quality & & & & \\
\hline Applicants & .0174 & .0239 & .0852 & .0316 & .0103 & .0431 \\
\hline Nancy Billings & Low & High & Medium & Low & MS/MBA & High \\
Stanley Kent & Medium & Medium & Low & Extreme & MS/MBA & Medium \\
Marsha Macon & High & Low & Medium & High & PhD & High \\
James Plowski & High & High & High & Medium & BS & Medium \\
\hline
\end{tabular}


Evaluation of Applicants: Lab Technician

\begin{tabular}{||l|c|c|c|c||}
\hline & Education & Experience & Technical & Dependability \\
\hline \multicolumn{1}{|c|}{ Applicants } & .0348 & .0418 & .1566 & .0770 \\
\hline Melvin harper & High & Medium & Medium & High \\
Elizabeth Ott & Medium & High & Medium & Medium \\
Heather Fink & High & Medium & Medium & Low \\
Synder Smith & Medium & Low & High & Medium \\
Symore Drone & Medium & Low & Low & High \\
Raymond Garner & Low & High & Low & Low \\
Mary Cunningham & High & High & Medium & Medium \\
\hline
\end{tabular}

Evaluation of Applicants: Quality Specialists

$\checkmark$

\begin{tabular}{||c|c|c|c||}
\hline & Education & Experience & Technical \\
\hline \multicolumn{1}{|c|}{ Applicants } & .0265 & .0378 & .0448 \\
\hline Sammy Morgan & BS & Medium & Medium \\
Prashant Gupta & Masters & Medium & High \\
\hline
\end{tabular}

Each applicant collects a rating score which is the total of the global weights of the corresponding intensities (obtained by multiplying the priority of each intensity by the global priority of its corresponding criterion) assigned to him or her for each of the criteria. The higher the score, the more qualified the applicánt is for the job. Table 4 shows the ranks of the applicants according to their scores.

Applicants Ranked by AHP Assigned Benefit

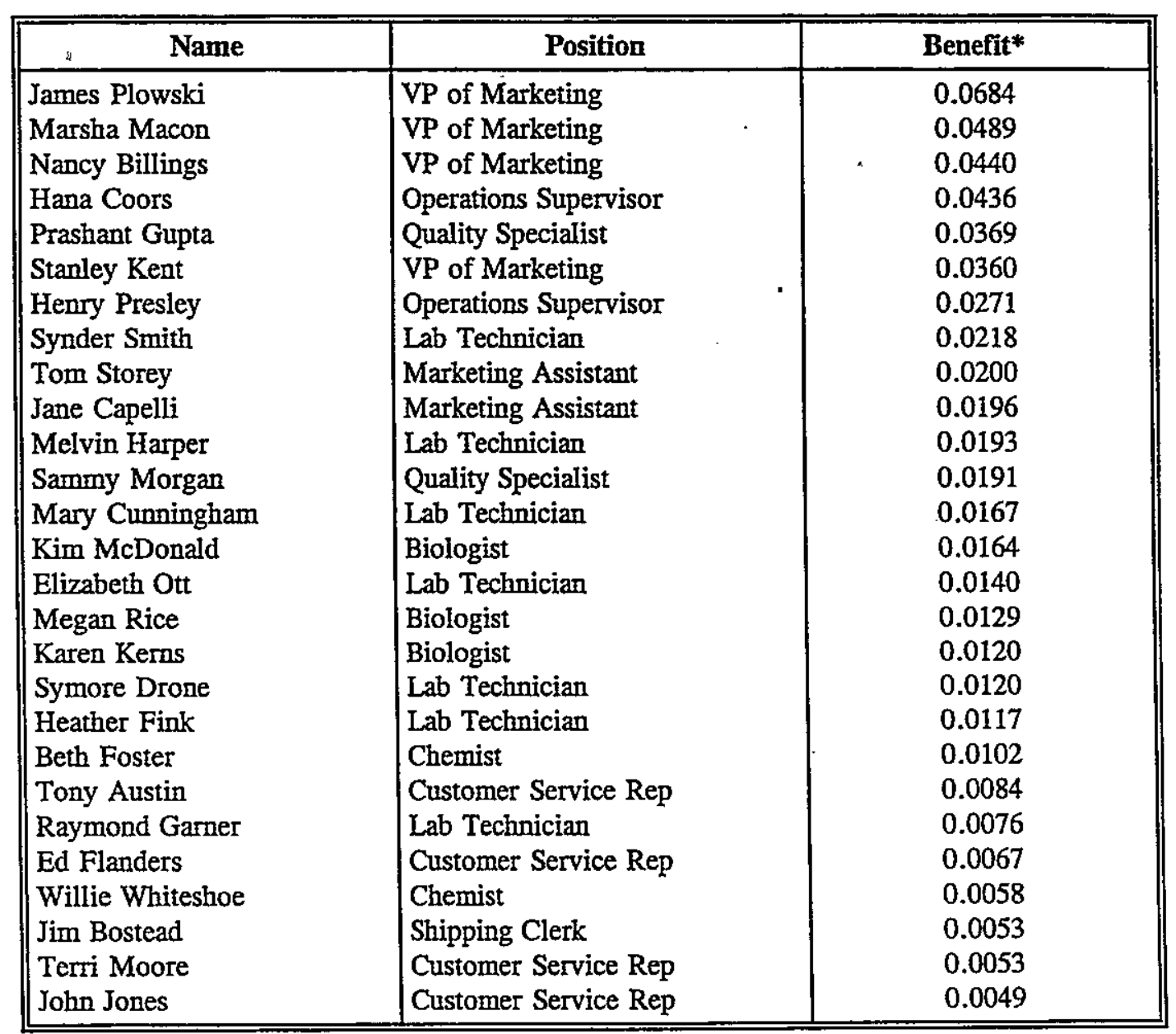


Applicants Ranked by AHP Assigned Benefit (continued)

\begin{tabular}{|l|l|c|}
\hline \multicolumn{1}{|c|}{ Name } & \multicolumn{1}{|c|}{ Position } & Benefit* \\
\hline Brian Buzelli & Biologist & 0.0044 \\
Teddy Star & Chemist & 0.0044 \\
Charles Young & Customer Service Rep & 0.0040 \\
Biff Van Swan & Shipping Clerk & 0.0031 \\
\hline
\end{tabular}

* Each employee's total value has been adjusted to account for differences in the number of elements in the departments. Note that there is only one position for R\&D Department and four positions for Marketing and Manufacturing Departments. To account for this difference, the lab technicians final rating was multiplied by $1 / 9$, and the other positions by $4 / 9$.

\section{Manpower Allocation}

We then use linear programming in the following two ways to determine who should be hired.

1) Optimizing the individuals

We use an objective function whose variables are the 31 individuals and whose coefficients are their corresponding priorities according to their benefits. The values of the variables are $(0,1)$ representing hired/not hired, subject to a, salary constraint and upper and lower bound constraints on the number of people. The salary constraint could utilize the actual salaries asked for than those given in the table.

\section{Maximize}

$$
\begin{aligned}
& .0684 \mathrm{X}_{1}+.0489 \mathrm{X}_{2}+.0440 \mathrm{X}_{3}+.0360 \mathrm{X}_{4}+.0196 \mathrm{X}_{5}+.0200 \mathrm{X}_{6}+.0049 \mathrm{X}_{7}+.0067 \mathrm{X}_{8}+.0053 \mathrm{X}_{9}+ \\
& .0084 \mathrm{X}_{10}+.0040 \mathrm{X}_{11}+.0031 \mathrm{X}_{12}+.0053 \mathrm{X}_{13}+.0193 \mathrm{X}_{14}+.0140 \mathrm{X}_{15}+.0117 \mathrm{X}_{16}+.0218 \mathrm{X}_{17}+ \\
& .0120 \mathrm{X}_{18}+.0076 \mathrm{X}_{19}+.0167 \mathrm{X}_{20}+.0044 \mathrm{X}_{21}+.0058 \mathrm{X}_{22}+.0102 \mathrm{X}_{23}+.0044 \mathrm{X}_{24}+.0120 \mathrm{X}_{25}+ \\
& .0129 \mathrm{X}_{26}+.0164 \mathrm{X}_{27}+.0191 \mathrm{X}_{28}+.0369 \mathrm{X}_{29}+.0271 \mathrm{X}_{30}+.0436 \mathrm{X}_{31}
\end{aligned}
$$

Subject to the salary constraint

$$
\begin{aligned}
& 120 \mathrm{X}_{1}+120 \mathrm{X}_{2}+120 \mathrm{X}_{3}+120 \mathrm{X}_{4}+50 \mathrm{X}_{5}+50 \mathrm{X}_{6}+40 \mathrm{X}_{7}+40 \mathrm{X}_{8}+40 \mathrm{X}_{9}+40 \mathrm{X}_{10}+40 \mathrm{X}_{11}+40 \mathrm{X}_{12} \\
& +140 \mathrm{X}_{13}+40 \mathrm{X}_{14}+40 \mathrm{X}_{15}+40 \mathrm{X}_{16}+20 \mathrm{X}_{17}+20 \mathrm{X}_{18}+20 \mathrm{X}_{19}+20 \mathrm{X}_{20}+50 \mathrm{X}_{21}+50 \mathrm{X}_{22}+50 \mathrm{X}_{23}+ \\
& 45 \mathrm{X}_{24}+45 \mathrm{X}_{25}+45 \mathrm{X}_{26}+45 \mathrm{X}_{27}+70 \mathrm{X}_{28}+70 \mathrm{X}_{29}+90 \mathrm{X}_{30}+90 \mathrm{X}_{31} \leq 520
\end{aligned}
$$

and to constraints on the number of people in each position:

$$
\begin{aligned}
& \mathrm{X}_{1}+\mathrm{X}_{2}+\mathrm{X}_{3}+\mathrm{X}_{4}=1 \\
& \mathrm{X}_{5}+\mathrm{X}_{6}=1 \\
& 1 \leq \mathrm{X}_{7}+\ldots+\mathrm{X}_{11} \leq 3 \\
& 0 \leq \mathrm{X}_{12}+\mathrm{X}_{13} \leq 1 \\
& 2 \leq \mathrm{X}_{14}+\mathrm{X}_{20} \leq 5 \\
& 0 \leq \mathrm{X}_{21}+\mathrm{X}_{22}+\mathrm{X}_{23} \leq 1 \\
& 1 \leq \mathrm{X}_{24}+\mathrm{X}_{27} \leq 2 \\
& 0 \leq \mathrm{X}_{28}+\mathrm{X}_{29} \leq 1 \\
& \mathrm{X}_{30}+\mathrm{X}_{31}=1
\end{aligned}
$$
;Vice President of Marketing
;Marketing Assistant
;Customer Service Representative
;Shipping Clerk
;Lab Technician
;Chemists
;Biologists
;Quality Specialists
;Operations Supervisor

The LP solution indicates that the following employees should be selected: 


\begin{tabular}{|l|l|c|}
\hline \multicolumn{1}{|c|}{ Name } & \multicolumn{1}{|c|}{ Position } & Salary \\
\hline James Plowski & VP Marketing & $\$ 120,000$ \\
Tom Storey & Marketing Assistant & $\$ 50,000$ \\
Tony Austin & Customer Service Rep. & $\$ 40,000$ \\
Melvin Harper & Lab Technician & $\$ 40,000$ \\
Synder Smith & $\$ 40,000$ \\
Kim McDonald & Lab Technician & $\$ 45,000$ \\
Prashant Gupta & Biologist & $\$ 70,000$ \\
Hana Coors & Quality Specialist & $\$ 90,000$ \\
\hline \multicolumn{2}{|l|}{ Total Salary } & $\$ 495,000$ \\
\hline
\end{tabular}

\section{2) Optimizing the positions}

In the second approach, we use an objective function whose variables and their coefficients are the nine positions and their corresponding priorities given in the fourth level of the selection hierarchy. The values of the variables are integers representing the number of vacancies in each position. This model determines the optimal number of vacancies to fill, and then selects the best applicants for the vacancies. The previous model did the selection based on the rating of the applicants, taking the relative importance of the positions into consideration. The salary constraint and the upper and lower bounds on personnel requirements are the same as before. When the exercise is completed, applicants with the highest scores in their category are chosen. We have:

Maximize $.2822 Y_{1}+.1076 Y_{2}+.0382 Y_{3}+.0000 Y_{4}+.0689 Y_{5}+.0000 Y_{6}+.0556 Y_{7}+.1360 Y_{8}+$ $.2187 \mathrm{Y}_{9}$ $2^{n+4}$

The coefficients are obtained from the 4 th level of the hierarchy adjusted by multiplying the Marketing positions by $4 / 9$, the $R \& D$ position by $1 / 9$, the Manufacturing positions by $4 / 9$, and then the results are normalized.

We have the salary constraint:

$$
120 \mathrm{Y}_{1}+50 \mathrm{Y}_{2}+40 \mathrm{Y}_{3}+40 \mathrm{Y}_{4}+40 \mathrm{Y}_{5}+50 \mathrm{Y}_{6}+45 \mathrm{Y}_{7}+70 \mathrm{Y}_{8}+90 \mathrm{Y}_{9} \leq 520
$$

and the departmental constraints:

$$
\begin{aligned}
& Y_{1}=1 \\
& Y_{2}=1 \\
& 1 \leq Y_{3} \leq 3 \\
& 0 \leq Y_{4} \leq 1 \\
& 2 \leq Y_{5} \leq 5 \\
& 0 \leq Y_{6} \leq 1 \\
& 1 \leq Y_{7} \leq 2 \\
& 0 \leq Y_{8} \leq 1 \\
& Y_{9}=1
\end{aligned}
$$

The second approach produces the following LP solution that is consistent with that of the first approach in terms of the number of vacancies filled in each position: 


\begin{tabular}{|c|c|c|c|}
\hline \multicolumn{4}{|c|}{ Employee Selection: Optimixing the positions } \\
\hline Position & Selection & Position Salary & Total Salary \\
\hline $\begin{array}{l}\text { VP Marketing } \\
\text { Marketing Assistant } \\
\text { Customer Service Rep. } \\
\text { Shipping Clerk } \\
\text { Lab Technician } \\
\text { Chemists } \\
\text { Biologists } \\
\text { Quality Specialists } \\
\text { Operations Supervisor }\end{array}$ & $\begin{array}{l}1 \\
1 \\
1 \\
0 \\
2 \\
0 \\
1 \\
1 \\
1\end{array}$ & $\begin{array}{l}\$ 120,000 \\
\$ 50,000 \\
\$ 40,000 \\
\$ 40,000 \\
\$ 40,000 \\
\$ 50,000 \\
\$ 45,000 \\
\$ 70,000 \\
\$ 90,000\end{array}$ & $\begin{array}{lr}\$ & 120,000 \\
\$ & 50,000 \\
\$ & 40,000 \\
\$ & 0 \\
\$ & 80,000 \\
\$ & 0 \\
\$ & 45,000 \\
\$ & 70,000 \\
\$ & 90,000\end{array}$ \\
\hline \multicolumn{3}{|c|}{ Total Salary } & $\$ 495,000$ \\
\hline
\end{tabular}

Note that optimization using LP is needed in this problem because BDS has allotted only $\$ 520,000$ to spend on salary and benefits for additional employees, while to fill the maximum number of vacancies would require $\$ 830,000$.

\section{Choosing the Best Employee Training Program (Peng and Huang, 1994)}

China National Publishing Industry Trading Corporation (CNPITC) is a diversified state-owned multibillion-Chinese-Yuar trading company located in Beijing. The Department of Publications in charge of the most important and the most profitable business activity of the company has clients in Taiwan, Hong Kong, Singapore, Japan and other Asian countries. However, the business has not been growing for the last few years because of internal competition, saturated market, termination of funding, and lack of flexibility in human resource hiring, firing, and compensating. The department foresees a potential market in western countries, but it is not well-known internationally and only a few of its employees have been exposed to westerin 'culture' or speak' their languages. Only twenty out of its' 90 fult-time employees are college graduates, and most of them are new employees.

The department decided to carry out extensive training programs. There are 7 alternative training programs that can be considered/for each trainee:

(1) An overseas 11 month MBA program, with an estimated cost of $\$ 40,000$ per trainee.

(2) An in-house training program, which costs less and would have a consideräble impact, but lacks exposure to an international environment.

(3) College program in Beijing, which costs only about $\$ 1500$ per student but the quality of its business program is not|as good as an overseas MBA program. Recruiting specialists, which costs about $\$ 10,000$ per person.

(2) $+(4)$ : Recruiting specialists and providing them with in-house training.

(2) $+(3)$ : Combining in-house training and college program.

(3) + (4): Recruiting specialists and providing them with college education.

The question is, what programs to choose, and how many people for each program? The training programs are evaluated using absolute measurement, based on their benefits and costs for the organization as a whole, as shown in the hierarchies below. 


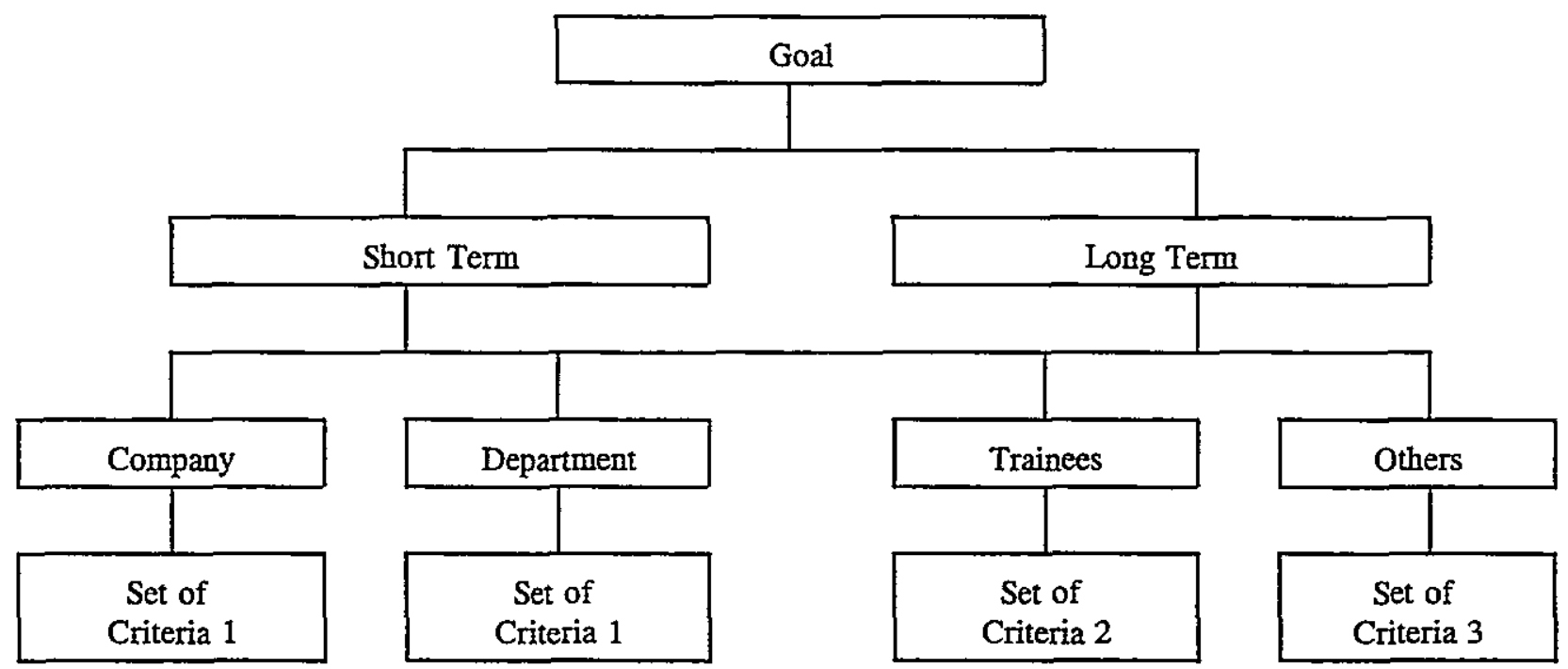

Set of Criteria 1: Culture, Productivity, International Contact, Domestic Contact, Quality, Knowledge. Set of Criteria 2: Set of Criteria 1 plus Personal Gains Set of Criteria 3: Set of Criteria 1 with International Contact and Domestic Contact combined into Contact

AHP of Costs

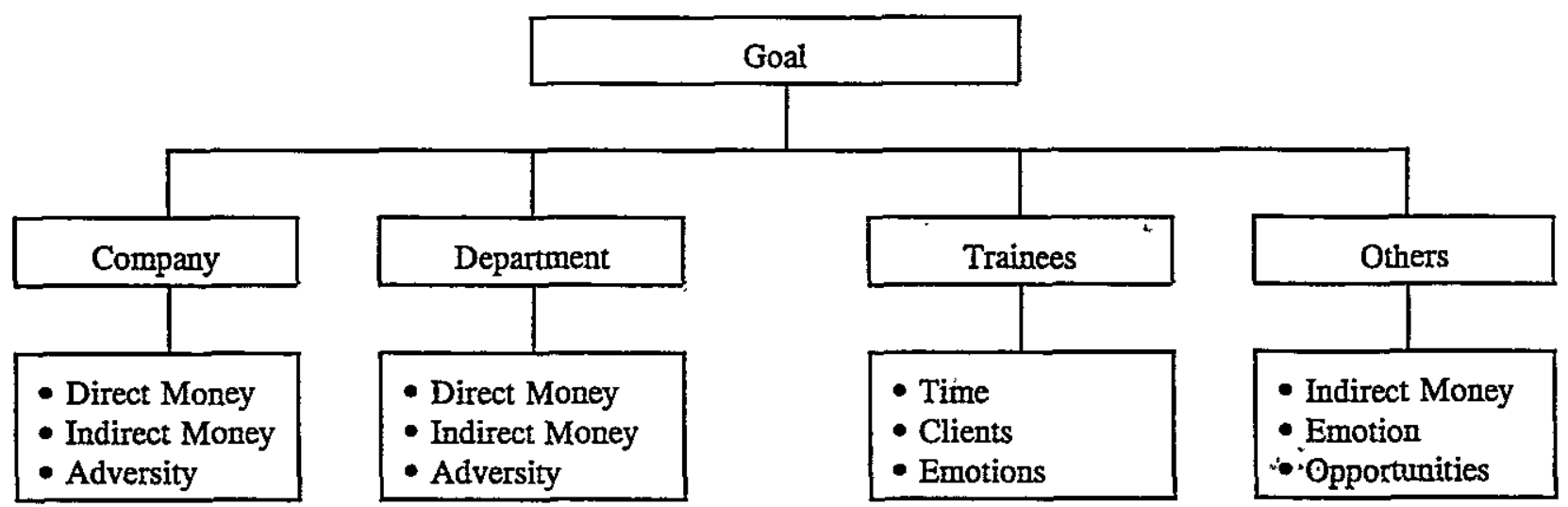

The analyses give the following result:

Benefits and Costs Analyses

\begin{tabular}{||c|c|c|c|c||}
\hline Variables & Alternatives & Benefits (B) & Costs (C) & B/C \\
\hline $\mathrm{X}_{1}$ & Overseas training (1) & 0.402 & 0.674 & 0.60 \\
$\mathrm{X}_{2}$ & In-house training (2) & 0.385 & 0.144 & 2.67 \\
$\mathrm{X}_{3}$ & College program (3) & 0.224 & 0.273 & 0.82 \\
$\mathrm{X}_{4}$ & Recruit specialist (4) & 0.278 & 0.156 & 1.78 \\
$\mathrm{X}_{5}$ & $(2)+(3)$ & 0.446 & 0.283 & 1.58 \\
$\mathrm{X}_{6}$ & $(2)+(4)$ & 0.635 & $0.308^{\circ}$ & 2.06 \\
$\mathrm{X}_{7}$ & $(3)+(4)$ & 0.299 & 0.305 & 0.98 \\
\hline
\end{tabular}

The $\mathrm{B} / \mathrm{C}$ ratios are used as the coefficients in the LP objective function. The constraints must satisfy the following assumptions:

a. A trainee in the overseas training program cannot participate in another program, and no trainee can take more than two programs in the same year.

b. The department cannot have more than 40 employees in training in the same year. 
c. The total funds available are $\$ 180,000$ per year. The overseas training program must not cost more than $\$ 160,000$ per year. The annual costs for the overseas training program and for recruiting specialists are $\$ 40,000$ and $\$ 10,000$ respectively per individual. The costs for the other training programs are assumed to be negligible.

d. In-house training programs must have more than 10 and less than 30 participants.

e. No more than 16 trainees attend college education, at least 2 people are chosen for each basic program, at least 2 trainees are sent to overseas training, and no more than 10 specialists are hired.

The LP formulation is as follows:

$$
\begin{aligned}
& \text { Maximize } .60 \mathrm{X}_{1}+2.67 \mathrm{X}_{2}+.82 \mathrm{X}_{3}+1.78 \mathrm{X}_{4}+1.58 \mathrm{X}_{5}+2.06 \mathrm{X}_{6}+.98 \mathrm{X}_{7} \\
& \text { subject to: } \\
& \mathrm{X}_{1}+\mathrm{X}_{2}+\mathrm{x}_{3}+\mathrm{x}_{4}+\mathrm{x}_{5}+\mathrm{x}_{6}+\mathrm{x}_{7} \leq 40 \\
& x_{1} \quad \geq 2 \\
& \mathrm{X}_{1} \quad \leq 4 \\
& \mathrm{x}_{4}+\mathrm{x}_{6}+\mathrm{x}_{7} \geq 2 \\
& \mathrm{X}_{4}+\mathrm{x}_{6}+\mathrm{x}_{7} \geq 10 \\
& \mathrm{x}_{2}+\mathrm{x}_{5}+\mathrm{x}_{6} \geq 10 \\
& \mathrm{x}_{2}+\mathrm{x}_{5}+\mathrm{x}_{6} \leq 30 \\
& \mathrm{x}_{3}+\mathrm{x}_{5}+\mathrm{x}_{7} \geq 2 \\
& X_{3}+X_{5}+X_{7} \leq 16
\end{aligned}
$$

The solution is given by:

$\begin{array}{lll}\mathrm{X}_{1} & \text { Overseas training program } & 2 \\ \mathrm{X}_{2} & \text { In-house training program } & 30 \\ \mathrm{X}_{3} & \text { College program } & 0\end{array}$

$\mathrm{X}_{4} \quad$ Specialists recruited (do not take any other program) 6
- $\mathrm{X}_{5} \quad$ In-house and College programs
$\mathrm{X}_{6} \quad$ Specialists.recruited and taking in-house training program

$\mathrm{X}_{7} \quad$ Specialists recruited and taking college program

\section{Examples with Synergy}

2

0

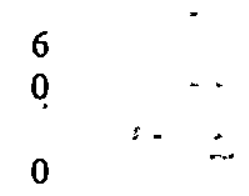

2

There are cases where a group of people taken together contribute more (or less) than the sum of what several members do individually. In the following examples, the costs are assumed to be dollar costs included as a constraint in the optimization problem.

$$
\begin{aligned}
& \text { Negative Synergy: }
\end{aligned}
$$

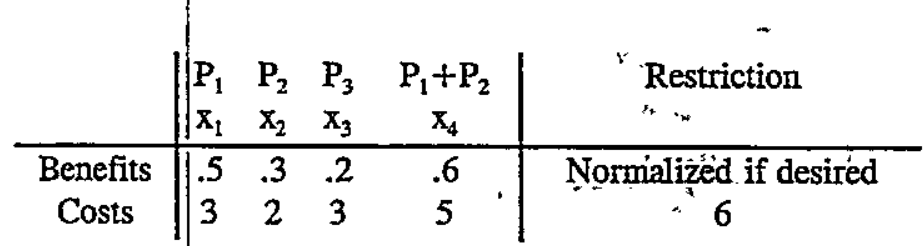

$$
\begin{aligned}
& \text { Problem: } \operatorname{Max} 0.5 \mathrm{X}_{1}+0.3 \mathrm{X}_{2}+0.2 \mathrm{X}_{3}+0.6 \mathrm{x}_{4} \\
& \text { S.T. } 3 x_{1}+2 x_{2}+3 X_{3}+5 x_{4} \leq 6 \\
& \text { and to: }
\end{aligned}
$$


We cannot have $X_{1}$ and $X_{2}$ together because then we would have $X_{4}$ and the other conditions would take over. That is preventing double counting.

Solution: $\mathrm{X}_{1}=1$ and $\mathrm{X}_{3}=1$

Positive Synergy:

\begin{tabular}{c|cccc|c} 
& $\mathrm{P}_{1}$ & $\mathrm{P}_{2}$ & $\mathrm{P}_{3}$ & $\mathrm{P}_{1}+\mathrm{P}_{2}$ & Restriction \\
& $\mathrm{X}_{1}$ & $\mathrm{x}_{2}$ & $\mathrm{x}_{3}$ & $\mathrm{x}_{4}$ & \\
\hline Benefits & .5 & .3 & .3 & .9 & Normalized if desired \\
Costs & 3 & 2 & 2 & 5 & 6
\end{tabular}

Problem: $\operatorname{Max} 0.5 \mathrm{X}_{1}+0.3 \mathrm{X}_{2}+0.3 \mathrm{X}_{3}+0.9 \mathrm{X}_{4}$

S.T. $\quad 3 X_{1}+2 X_{2}+2 X_{3}+5 X_{4} \leq 6$

and to:

$$
\begin{array}{ll}
\text { Exclusion: } & \text { Preventing double counting } \\
X_{1}+X_{4} \leq 1 & X_{1}+X_{2} \leq 1 \\
X_{2}+X_{4} \leq 1 & \\
X_{1}, X_{2}, X_{3}, X_{4} \in\{0,1\} &
\end{array}
$$

Solution: $\mathrm{X}_{4}=1$

Multiple Synergy/Restrictions:

\begin{tabular}{l|cccccccc|c} 
& $\mathrm{P}_{1}$ & $\mathrm{P}_{2}$ & $\mathrm{P}_{3}$ & $\mathrm{P}_{4}$ & $\mathrm{P}_{5}$ & $\mathrm{P}_{1}+\mathrm{P}_{2}$ & $\mathrm{P}_{2}+\mathrm{P}_{3}$ & $\mathrm{P}_{1}+\mathrm{P}_{2}+\mathrm{P}_{3}$ & Restriction \\
& $\mathrm{x}_{1}$ & $\mathrm{x}_{2}$ & $\mathrm{x}_{3}$ & $\mathrm{x}_{4}$ & $\mathrm{x}_{5}$ & $\mathrm{x}_{6}$ & $\mathrm{x}_{7}$ & $\mathrm{x}_{8}$ & \\
\hline Benefits & .1 & .2 & .3 & .4 & .5 & .5 & .7 & .3 & Normalized if desired \\
Cost 1 & 2 & 4 & 6 & 8 & 10 & 6 & 10 & 12 & 25 \\
Cost 2 & 10 & 3 & 8 & 7 & 6 & 19 & 17 & 27 & 35
\end{tabular}

Problem: $\operatorname{Max} 0.1 \mathrm{X}_{1}+0.2 \mathrm{X}_{2}+0.3 \mathrm{X}_{3}+0.4 \mathrm{X}_{4}+0.5 \mathrm{X}_{5}+0.5 \mathrm{X}_{6}+0.7 \mathrm{X}_{7}+0.8 \mathrm{X}_{8}^{\prime}$

$$
\text { ST: } \begin{array}{r}
2 \mathrm{X}_{1}+4 \mathrm{X}_{2}+6 \mathrm{X}_{3}+8 \mathrm{X}_{4}+10 \mathrm{X}_{5}+6 \mathrm{X}_{6}+10 \mathrm{X}_{7}+12 \mathrm{X}_{8} \leq 25 \\
10 \mathrm{X}_{1}+3 \mathrm{X}_{2}+8 \mathrm{X}_{3}+7 \mathrm{X}_{4}+6 \mathrm{X}_{5}+19 \mathrm{X}_{6}+17 \mathrm{X}_{7}+27 \mathrm{X}_{8} \leq 35
\end{array}
$$

and to:

$$
\begin{array}{llll}
\text { Exclusion: } & & \text { Preventing double co } \\
X_{1}+X_{6}+X_{8} & \leq 1 & X_{1}+X_{2} & \leq 1 \\
X_{2}+X_{6}+X_{7}+X_{8} \leq 1 & X_{2}+X_{3} & \leq 1 \\
X_{3}+X_{7}+X_{8} & \leq 1 & X_{1}+X_{2}+X_{3} \leq 1 \\
& & X_{1}+X_{7} & \leq 1 \\
& & X_{3}+X_{6} & \leq 1
\end{array}
$$

$$
\mathrm{X}_{1}, \mathrm{X}_{2}, \mathrm{X}_{3}, \mathrm{X}_{4}, \mathrm{X}_{5}, \mathrm{X}_{6}, \mathrm{X}_{7}, \mathrm{X}_{8} \in\{0,1\}
$$

\section{The Problem of Intangible Objective Function and Constraints}

As far as the occurrence of tangible and intangible measurement in linear programming, ther are four types of problems to consider: (1) both coefficients and variables are tangible as in the usual LP formulation, (2) the variables are tangible but the coefficients are intangible (determined in the usual way through paired comparisons), (3) the coefficients are tangible but the variables are intangible, and (4) both coefficients and variables are intangible.

We note that if the constraining constants (i.e., the $b_{i}$ ), but not the left hand sides of the constraints, are multiplied by the same constant, then the solution of an LP problem is also multiplied by that constant. Thus, one may be able to generate the right side constants through paired comparisons, obtain the solution, and then increase or decrease its value experimentally by multiplying by a constant to obtain the desired 
solution.

An example of an LP problem with an intangible constraint is the following hypothetical diet problem in which the cost of foods is to be minimized subject to three constraints. The first two constraints are vitamin $\mathrm{A}$ and $\mathrm{C}$ requirements, whereas the third constraint is a taste requirement. Its left side coefficients are determined by comparing the relative desirability of taste in the relative amount of each food to be consumed are determined through paired comparison and sum to one. The right side is determined by comparing three levels of taste, poor, medium, and high, and obtaining the relative values $0.1,0.2$, and 0.7 respectively and then requiring that the taste be at least high. Thus the problem is:

Minimize: $\quad 7 \mathrm{X}_{1}+\mathrm{X}_{2}$

ST:

$$
\begin{aligned}
3 \mathrm{X}_{1}+\mathrm{X}_{2} & \geq 12(\text { Vitamin } \mathrm{A}) \\
\mathrm{X}_{1}+\mathrm{X}_{2} & \geq 6 \text { (Vitamin } \mathrm{C}) \\
0.2\left[\frac{x_{1}}{x_{1}+x_{2}}\right]+0.8\left[\frac{x_{2}}{x_{1}+x_{2}}\right] & \geq 0.7 \text { (Taste) which simplifies to } \\
-0.5 \mathrm{X}_{1}+0.1 \mathrm{X}_{2} & \geq 0
\end{aligned}
$$

The solution to the problem without the taste constraint is $X_{1}=0$ and $X_{2}=12$ and the value of the objective function is 12 . With the taste constraint, the solution is $X_{1}=5$ and $X_{2}=1$ and the value of the objective function is 36 . Thus one must pay more to satisfy taste requirement. More examples are needed to clarify and encourage practitioners to create LP problems with only intangible constraints and intangible variables.

\section{Conclusion}

We have shown through examples how to apply absolute measurement of the AHP together with LP to determine which positions to fill and which candidates to hire to satisfy salary and eimployee number to satisfy for each position. We also showed how the AHP enables one to include synergy in its prioritization to determine the best combination of people to hire.

\section{References}

Craft, J. A. (1995), Human Resource Planning: Its Roots and Development in Management Thought, Working Paper, Katz Graduate School of Business, University of Pittsburgh, Pittsburgh.

Fisher, C.D. et. al. (1993), Human Resource Management, Houghton Mifflin Company, Boston.

Gabler, C. and Prado, D. (1994), A Manpower Allocation Model for Biological Detection Systems, BQOM 2410 Class Project, University of Pittsburgh.

Mathis, R.L. and Jackson, J. H. (1991), Human Resource Management, Minneapolis/St. Paul: West Publishing Corp.

Milovich, G.T. and Boudreau, J. W. (1991) Human Resource Management, Irwin Publishers.

Noe, R.A. et. al. (1994), Human Resource Management: Gaining a Competitive Advantage, Burr Ridge, IL.: Austen Press,

Peng, Yuqing and Yun-Kwan Huang (1994). Choosing the Best Employee Training Programs, BQOM 2410 Class Project, University of Pittsburgh.

Shuler, R.S. and Huber, V. L. (1993), Personnel and Human Resource Management, New York: West Publishing Corp. 